\title{
Seismic vulnerability assessment and characterisation of the buildings on Faial Island, Azores
}

\author{
Filipe Neves · Aníbal Costa • Romeu Vicente • \\ C. Sousa Oliveira · Humberto Varum
}

Received: 13 April 2010 / Accepted: 13 April 2011 / Published online: 10 May 2011

(C) Springer Science+Business Media B.V. 2011

\begin{abstract}
The earthquake of the 9th of July 1998 that hit in the central group of the Azores archipelago greatly affected the islands of Faial, Pico and São Jorge, reaching a magnitude of Mw 6.2 with the epicentre located about $15 \mathrm{~km}$ northeast of the Faial Island. This earthquake allowed the collection of an unprecedented quantity of data concerning the characterisation of the building stock and the damage suffered by construction. This is the main purpose of this research, consisting essentially of three main aspects: (i) A detailed characterisation of the building stock, assigning a five category classification, from old traditional rubble stone masonry to reinforced concrete moment framed buildings; (ii) A detailed damage grade classification based on the different damage mechanisms observed; and, (iii) A seismic vulnerability assessment of the building stock. The results of the vulnerability assessment together with the building stock database and damage classification were integrated into a GIS tool, allowing the spatial visualation of damage scenarios, which is potentially useful for the planning of emergency response strategies and retrofitting priorities to mitigate and manage seismic risk.
\end{abstract}

Keywords Faial Island, Azores · Masonry buildings $\cdot$ Seismic risk ·

Seismic vulnerability $\cdot$ Damage classification

\section{Introduction}

The evaluation of the seismic risk of a built-up area is associated with the level of local hazardousness, building vulnerability and level of exposure. Within this holistic approach

F. Neves $\cdot$ A. Costa $\cdot$ R. Vicente $\cdot$ H. Varum

Department of Civil Engineering, University of Aveiro, Aveiro, Portugal

C. S. Oliveira

Department of Civil Engineering and Architecture, Technical University of Lisbon, Lisbon, Portugal

F. Neves $(\varangle)$

Campus Universitário de Santiago, 3810-193 Aveiro, Portugal

e-mail: fjneves@gmail.com 
that defines seismic risk, of all three variables, building vulnerability is the one that assumes crucial importance. Not only because of its obvious physical consequences in the occurrence of a seismic event, but also because it is possible to intervene, improving the seismic behaviour of existing buildings by reducing their level of vulnerability and as a result the level of physical damage and loss to economy and life as consequence of a seismic event.

Over the last few decades, seismic risk evaluation, as well as that for other natural hazards, is of increasing concern and considered to have an essential role in the urban planning and risk management of prone areas (Campos Costa et al. 2009; Lantada et al. 2010) such as the Azores archipelago. The development of vulnerability assessment studies, in urban centres or rural areas, fundamentally aim to mitigate seismic risk, as well as identify building fragilities.

Ten years after the 1998 earthquake, information was gathered from several research reports and papers, and collated in the book, "Sismo 1998 Açores-uma década depois" by Oliveira et al. (2008). All data was gathered over an 8 month period in 2007, funded by the "Secretaria Regional da Habitação e Equipamento" of the Faial Island. A GIS (Geographic Information System) tool was used (ArcGis 2005) since it allowed spatial analysis, facilitated management of the information database and allowed mapping of buildings characteristics and features as well as the information produced from the seismic vulnerability assessment.

The main purpose of this work was to assess the seismic vulnerability of the buildings in the Faial Island, analysing the performance of the most representative construction types. Moreover, this research has contributed to building characterisation and damage classification. Within this purpose, three different approaches were followed. Firstly, a thorough characterisation of the building stock was carried out, describing the types of the buildings and structural characteristics, leading to the development of a database. Secondly, an original qualitative classification of the observed damage based on the typical damage mechanisms of stone masonry buildings was defined. Finally, the seismic vulnerability assessment of the building stock of the Faial Island was carried out using a statistical model developed by Vicente (2008). This method is an improvement on the methodology of the National Group for Earthquakes Defence (GNDT-SSN 1994) based on the vulnerability assessment methodology created by Giovinazzi (2005). With the methodology adopted by the seismic vulnerability evaluation of masonry buildings, a vulnerability index is obtained for each building and it is possible to estimate the physical damage, construct fragility curves and estimate human and economic losses. The construction of seismic scenarios using a spatial analysis tool (ArcGis 2005) can provide georeferenced information and integrate the entire probabilistic algorithm into the generation of different intensity defined risk scenarios.

\section{Building characterisation}

\subsection{Construction types}

This study characterises the building stock before the seismic event of July 1998 into several types of construction system (roof and floor structure, type of vertical resisting structure, type of partition walls).

The building stock in Faial and Pico Islands before the seismic event of July 1998 was mostly constituted of a traditional architectural typology. This traditional architecture has a simple construction scheme: stone masonry load-bearing walls and timber floor slabs and roof trusses. The fact that the islands of the Azores were affected by seismic events over the last decades, has resulted in the reconstruction, strengthening and modification of the traditional building stock, contributing to a variety of building types. Building a database 
Table 1 Types of constructive system

\begin{tabular}{|c|c|c|c|}
\hline Type & Vertical structure & Floor type & Roof type \\
\hline TC Traditional construction & Stone masonry & Timber & Timber truss \\
\hline $\begin{array}{l}\text { ATC ltered traditional } \\
\text { building }\end{array}$ & Stone masonry & $\begin{array}{l}\text { Reinforced concrete } \\
\text { (slabs in kitchen or } \\
\text { WC) }\end{array}$ & Timber truss \\
\hline CC Current construction & Reinforced concrete & Reinforced concrete slabs & $\begin{array}{l}\text { Reinforced concrete } \\
\text { or Timber }\end{array}$ \\
\hline MC1 Mixed construction 1 & Stone masonry stone & Reinforced concrete slabs & Timber truss \\
\hline MC2 Mixed construction 2 & $\begin{array}{l}\text { Reinforced concrete } \\
\text { and stone masonry }\end{array}$ & $\begin{array}{l}\text { Timber and } \\
\text { Reinforced concrete } \\
\text { slabs }\end{array}$ & Timber truss \\
\hline MC3 Mixed construction 3 & Reinforced concrete & Reinforced concrete slabs & $\begin{array}{l}\text { Reinforced concrete } \\
\text { or Timber truss }\end{array}$ \\
\hline
\end{tabular}

of construction features allows the reproduction of more realistic models in order to obtain seismic damage scenarios (Zonno et al. 2009).

Table 1 shows the catalogued construction types: traditional construction (TC), altered traditional building (ATC), current construction (CC) and mixed construction (MC). With this cataloguing of the building stock, it is later possible to correlate the damage types for each construction system, as well as understand the overall structural behaviour of each building type.

A building is considered traditional (TC) when its exterior load-bearing walls (façade and gable end walls) are stone masonry. The main façade and inside face have wide openings for windows and doors with lintels, the foundation system supporting the load-bearing walls are usually made of stone rubble. The thickness of the masonry walls is typically constant at about $66 \mathrm{~cm}$ (equivalent to 1 "côvado"- -an ancient measure of length). The horizontal diaphragms are made of timber supported by timber beams, usually of Wattle and Sugi species. The roof structure is typically a two sloped pitched timber structure. The partition walls usually include timber filled trusses. The traditional rural constructions are usually single storey or two-storey buildings.

Single storey buildings are more modestly built and located in areas of flat terrain. Twostorey buildings usually take advantage of the natural slope of the terrain, and include a basement (or, more commonly, a half basement). The traditional urban construction is part of a building aggregate, usually two to three storeys in height, rarely exceeding four stories. This construction, although having a more complex internal organisation and regardless of the size, normally has a secondary compartment where the kitchen is located, perpendicular to the main construction.

The altered traditional construction (ATC) resembles a traditional building, consisting only in the replacement of the timber floor structure (planks and beams) for a reinforced concrete slab, and again being supported by load-bearing stone masonry walls. This replacement is only partially made, typically in the service areas (kitchen and bathrooms). The current constructions (CC) buildings have a moment resistant reinforced concrete frame with masonry infill walls (confined concrete blocks), with floor slabs and roof structure in reinforced concrete. The mixed construction type 1 (MC1) corresponds to the replacement of the floor diaphragm (plank and timber beams) by a reinforced concrete slab supported by load-bearing stone masonry walls, with the possible existence of inner slab columns. For this construction type, the partition walls consist of concrete blocks or wooden lath work, however the timber structure of the roof is maintained. Mixed construction type 2 (MC2) is 


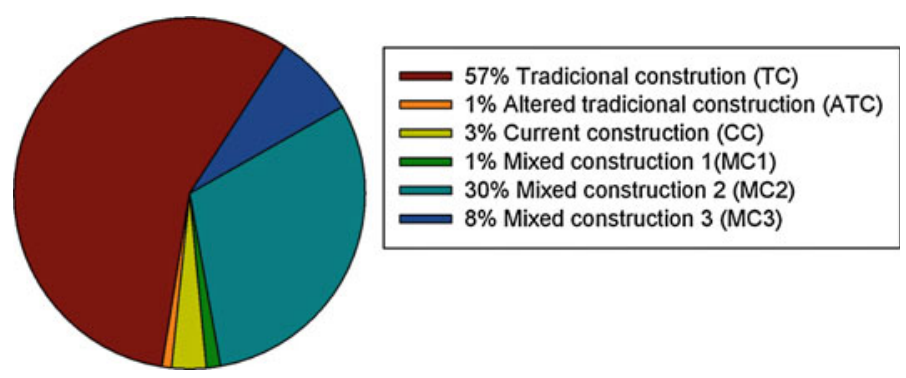

Fig. 1 Construction types. Distribution of the construction system types in Faial Island (sample of 2305 buildings dated from July 1998)

characterised by a greater degree of intervention related to the evolution of the building. This new extension is an entirely reinforced concrete structure (columns, beams and slabs) with a concrete block infill. The structural elements of the original construction (roof, floors and walls) are preserved. Finally the mixed construction type 3 (MC3) is characterised as current construction and preserves the original stone masonry wall as a fill element and not as structural element. Figure 1 presents the statistics for the distribution of the different construction types.

\subsection{Roof structures}

The support structure for the roofs in the central group of the Azores is essentially of two types (see Fig. 2). The roof structures without timber trusses are subdivided into "French", "scissor" and "horse" type. The types of roof with timber trusses are typically closed trusses. Both consist of two sloped timber structural elements. The roof rafters vary in dimensions between $0.14 \times 0.05 \mathrm{~m}$ and $0.19 \times 0.07 \mathrm{~m}$, spaced at 0.35 to $0.40 \mathrm{~m}$, which supports the ceiling. The rafters are connected to the ridge beam at the top, and at the bottom are supported by a wall plate, usually with a transverse section of $0.10 \times 0.10 \mathrm{~m}$, which is connected to the inner leaf of the masonry wall. This wall plate runs throughout the perimeter of the wall, constituting a type of ring-beam. The ceiling joists are spaced from 2 to $2.5 \mathrm{~m}$. For the urban buildings the "French" and "horse" type trusses (Fig. 2b,c) were more frequently observed. The "scissor" roof truss type is more common in rural buildings (Fig. 2d). Over the rafter beams the tile battens are fixed over which regional ceramic tiling is laid. The tile battens contributes to the overall stiffness of the roof and promotes the consolidation of the structure.

\subsection{Floor structures}

The most common type of floor structure is constituted of timber planks and timber beams. The timber beams are spaced at $0.40 \mathrm{~m}$ and are supported over the stone masonry walls (see schematic in Fig. 3) spanning from 3.5 to $4.0 \mathrm{~m}$. This wall plate allows a better distribution of the dead and live loads along the wall length, also allowing a better in-plane structural stiffness and strength distribution. The timber flooring is constituted of timber planks with a thickness varying between 2.2 and $2.5 \mathrm{~cm}$, nailed to the timber framework. In some buildings at the ground floor level the beams are laid over mudsills with a $0.10 \times 0.10 \mathrm{~m}$ cross-section.

In some buildings the traditional timber floor structures were substituted by reinforced concrete slabs. In some particular cases, a slender reinforced concrete slab has been constructed over the timber structure, using it as formwork, especially in the service areas of the 

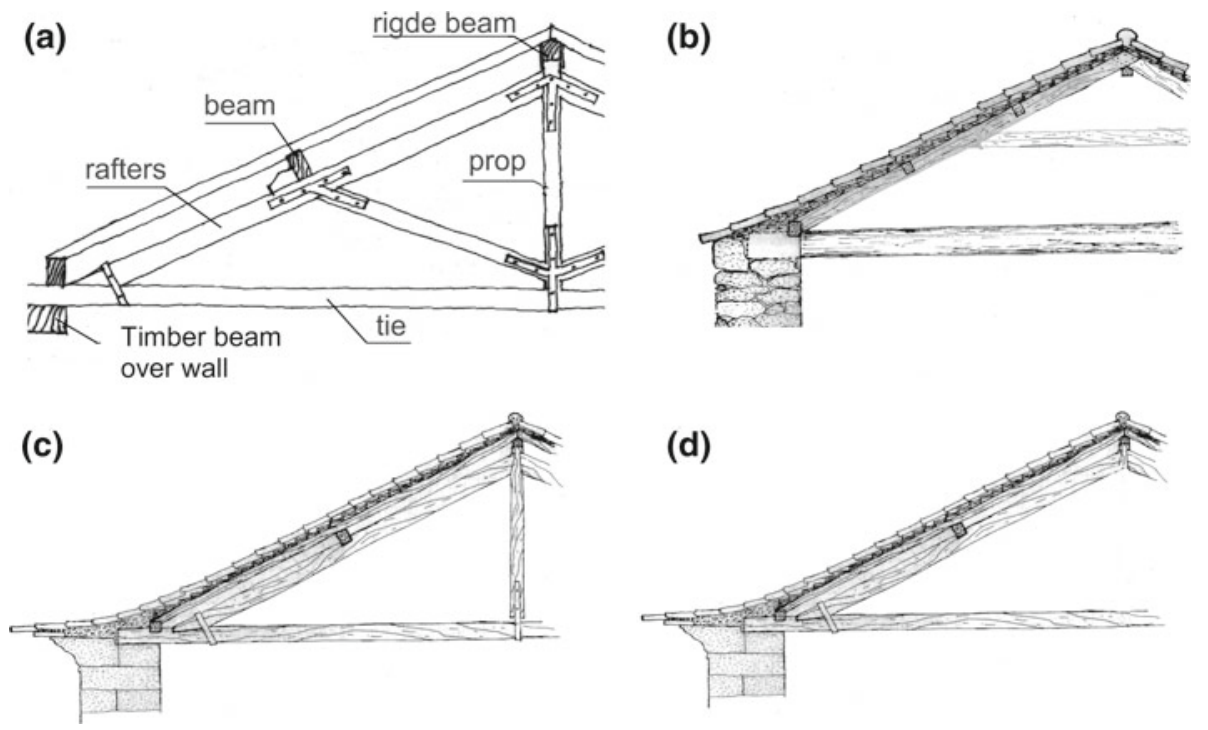

Fig. 2 Types of roof structures. Geometry of the types of roofs in the central group of the Azores and the structural timber elements: a typical roof (closed truss); b "French" type roof; c "horse" type roof; d "scissor" type roof

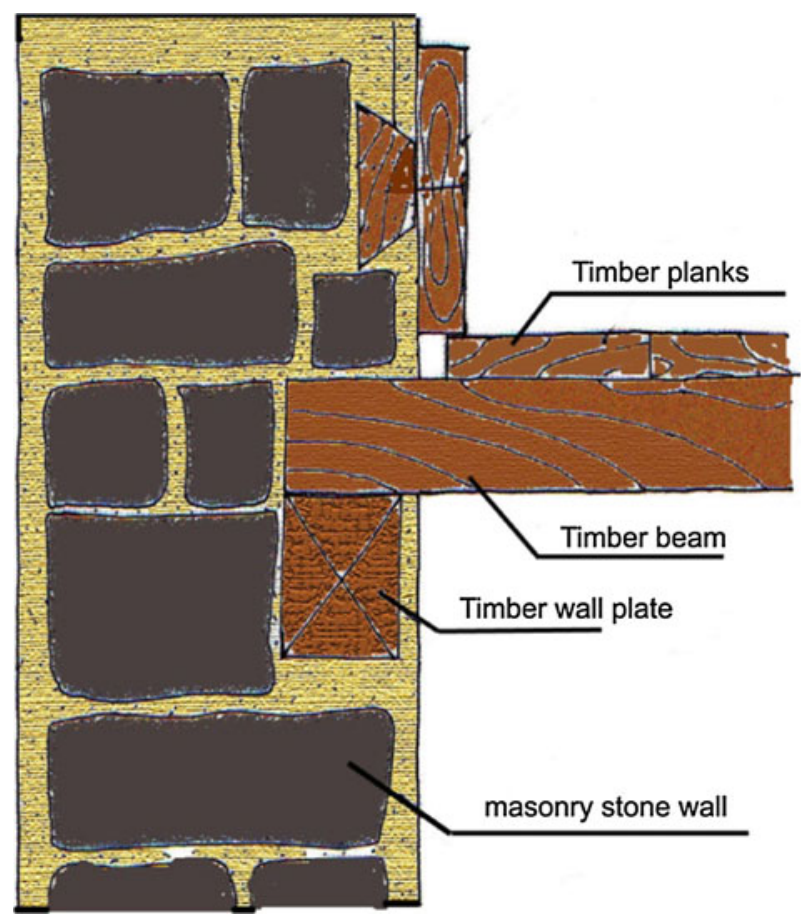

Fig. 3 Common masonry wall-timber floor connection 
(a)

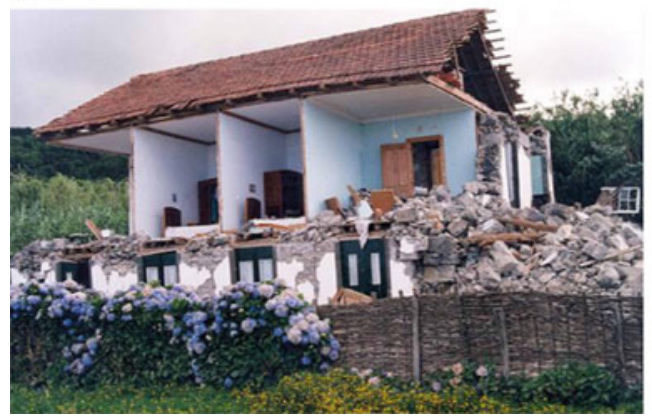

(b)

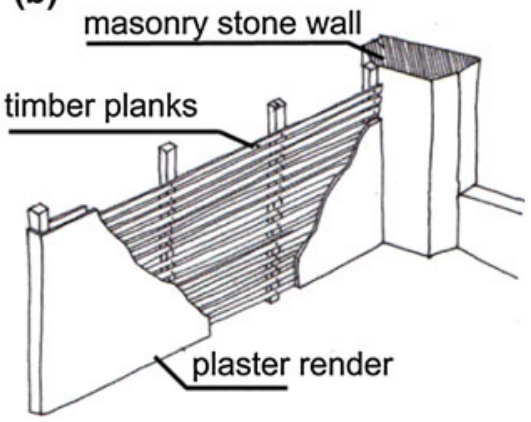

Fig. 4 Interior wood partition walls. a Partition walls prevent the roof collapse after the collapse of the exterior masonry walls; b detail of a typical partition wall (Lamas 2003)

house (kitchen and bathroom). Amplified areas or extensions of these traditional buildings are usually constructed by resorting to reinforced concrete, resulting in the coexistence of two types of floor structure which is very unfavourable in terms of seismic performance due to pounding effects.

\subsection{Partition walls}

The partition walls have also a structural function. Despite the lower stiffness and strength, they ultimately contribute to the bracing and overall resistance of the building. The 1998 earthquake led to the total collapse of the exterior enclosure walls of some buildings, leaving only the partition walls standing to support the roof structure (Fig. 4a). The partition walls at the ground floor level are generally thicker and heavier, built of stone masonry or concrete blocks, and contributing to a greater shear resistance of the building. The interior walls are constructed of timber planks and posts on both sides, at a spacing of 0.50 to $0.70 \mathrm{~m}$ (Fig. $4 \mathrm{~b}$ ). Timber strips are nailed to the planks which are covered with lime or clay mortar, and occasionally with the addition of animal hair (Costa 2002). Another type of partition wall, more common in more poorly constructed buildings, consist only of several timber planks that vary in quality and size. In common construction, partition walls are made of concrete blocks and in some cases the use of gypsum plaster board was also observed.

\subsection{Exterior enclosure walls}

When referring to stone, there are different types of external masonry walls (Fig. 5) dependent on the wealth of their original owners, as well as the location of the building, the most common being basalt, trachyte and volcanic tuff. The average thickness of the external stone masonry walls ranges from 0.65 to $0.70 \mathrm{~m}$. The masonry walls of better quality are built with regular prepared stone, Double leaf masonry walls are of the same width and the gap between the two leafs are filled with rubble, mud and lime mortar. The double leaf masonry wall can be also connected by a transverse stone layer spaced about $1.5 \mathrm{~m}$ in height (see Fig. 5). The three leaf masonry wall is usually thicker and its interior leaf is constituted of small stones and clay.

The rendering of the external stone masonry is variable. The most common rendering solution is composed of a mixture of clay and lime, about $2 \mathrm{~cm}$ in thickness, over which a fine lime and sand mortar is applied. The addition of volcanic ash is commonly used in the 


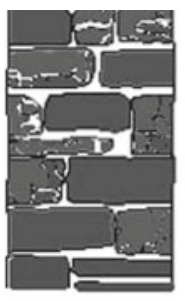

single leaf

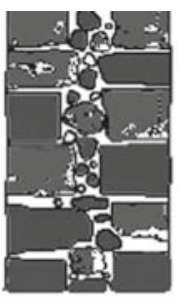

double leaf

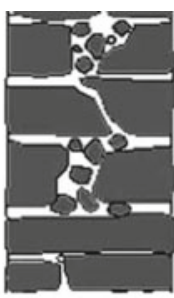

double leaf with transversal connection

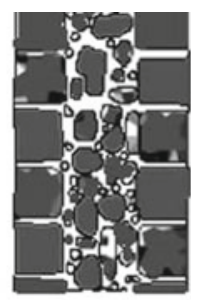

three leaf

Fig. 5 Types of external stone masonry walls

renders (Costa 2002). In the current buildings, the predominant wall type is made of concrete blocks of different thickness.

\section{Damage assessment and classification}

In this section a damage classification proposal for the traditional masonry building stock of the Azores islands will be presented. This proposal catalogues the damage suffered to masonry constructions similar to the classification used to characterise the damage of churches developed in Italy (Giovinazzi and Lagomarsino 2003). The damage assessment survey was undertaken in different stages and by analysing different levels of information: (i) photographic elements and datasheets filled by technicians of the civil protection body and Ministry of Housing and Equipment days after the earthquake; (ii) appraisal and inspection reports carried out by engineers before designing retrofitting solutions; (iii) in-situ observations of non retrofitted buildings in 2006. All this information was gathered and compiled in the scope of a regional government project (see Neves 2008).

This research is based on the damage evaluated from the exterior of the buildings, aiding to describe the typical behaviour of the building and damage mechanisms, particularly for the Faial Island.

The damage classification of damage types was based on the observation of a photographic catalogue of the entire building stock. By analysing the information gathered, different damage patterns that depend on the location of buildings were identified (Neves 2008). This allowed evaluation of the intensity and direction of the earthquake. The exterior damage observed was classified into 5 categories as follows: slight cracking, moderate cracking, extensive cracking, partial collapse, heavy damage (see Fig. 6).

Slight cracking (D1) (see Fig. 7) includes the widespread cracking around openings and hair line cracks (cracks of less than $1 \mathrm{~mm}$ in width).

Moderate cracking damage (D2) (see Fig. 8) includes typical shear cracking, involving relative movement between stones and the detachment of the wall rendering, without out-ofplane movement of the walls. If out-of-plane movements occurs the damage is then classified as extensive cracking (D3) (see Fig. 9).

Partial collapse damage (D4) is associated with the collapse of structural elements. In Fig. 10 the collapse mechanisms that can occur to gable end walls, roof structures, front walls and corner angles are shown. The arrows indicate the direction of the out-of-plane movement (damage mechanism) associated with the cracking pattern. In order to obtain detailed information of the observed damage, the partial collapse damage category was divided in 


\section{D1}

Slight cracking

\begin{tabular}{|l|l}
\hline D1G & Gable end wall \\
D1F & Front wall \\
D1GF & Gable end wall; Front wall
\end{tabular}

\section{D2}

Moderate cracking

\begin{tabular}{l|l}
\hline D2G & Gable end wall \\
D2F & Front wall \\
D2GF & Gable end wall; Front wall
\end{tabular}

\section{D3}

Extensive cracking

\begin{tabular}{|l|}
\hline D3G \\
D3F \\
D3GF \\
D3C \\
\hline
\end{tabular}

Gable end wall

Front wall

Gable end wall; Front wall

Corner angle

Observed damage

D4

Partial collapse

\begin{tabular}{|l|}
\hline D4G \\
D4F \\
D4R \\
D4C
\end{tabular}

\begin{tabular}{l|c|c|c|}
\cline { 2 - 4 } Gable end wall & $\mathrm{D} 4 \mathrm{G} 1$ & $\mathrm{D} 4 \mathrm{G} 2$ & $\mathrm{D} 4 \mathrm{G} 3$ \\
\cline { 2 - 4 } $\begin{array}{l}\text { Front wall } \\
\text { Roof }\end{array}$ & $\mathrm{D} 4 \mathrm{~F} 1$ & $\mathrm{D} 4 \mathrm{~F} 2$ & $\mathrm{D} 4 \mathrm{~F} 3$ \\
\cline { 2 - 4 } Corner angle & $\mathrm{D} 4 \mathrm{R} 1$ & $\mathrm{D} 4 \mathrm{R} 2$ & $\mathrm{D} 4 \mathrm{R} 3$ \\
\cline { 2 - 4 } & $\mathrm{D} 4 \mathrm{C} 1$ & $\mathrm{D} 4 \mathrm{C} 2$ & $\mathrm{D} 4 \mathrm{C} 3$ \\
\hline
\end{tabular}

\section{D5}

Heavy damage

\begin{tabular}{ll|}
\hline D5R & Roof \\
D5G & Gable wall \\
D5F & Front wall \\
D5T & Total collapse
\end{tabular}

Fig. 6 Classification of building damage: 5 categories (slight cracking, moderate cracking, extensive cracking, partial collapse and heavy damage) and the corresponding sub-categories depending on the damage location. On the right the designation adopted for collapse scenarios depending on the percentage of damage is presented
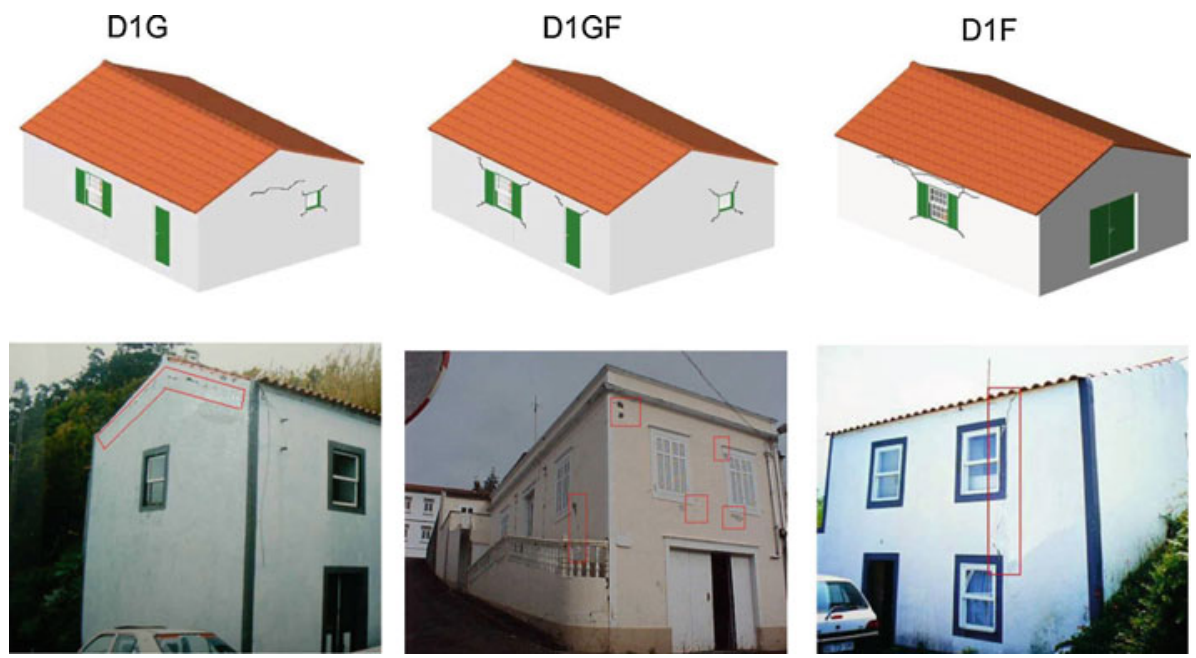

Fig. 7 Slight cracking damage examples (D1). D1G shows slight cracking in gable end wall, D1GF in gable end wall and front wall and D1F in front wall 

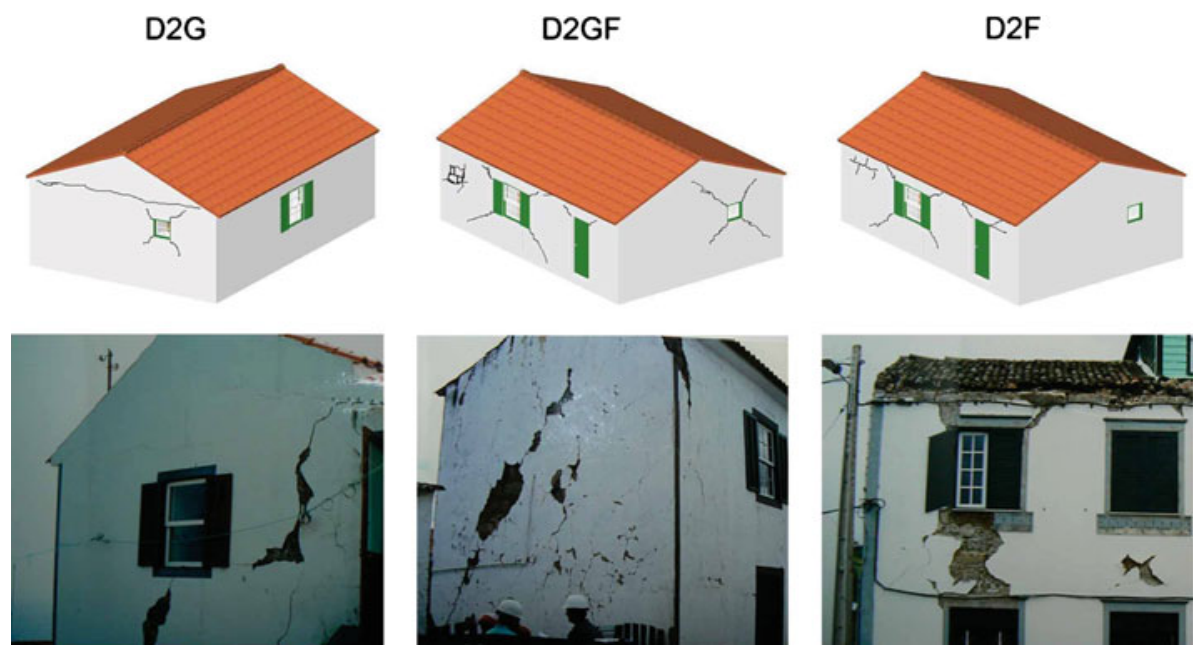

Fig. 8 Moderate cracking examples (D2). D2G moderate damage to gable end wall, D2GF to gable end wall and front wall and D2F to front wall
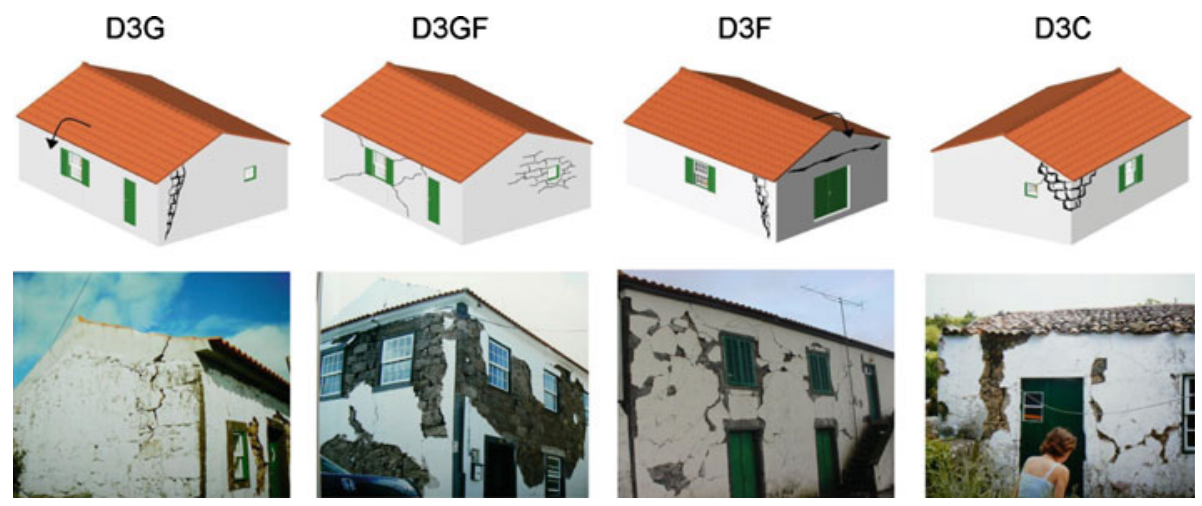

Fig. 9 Extensive cracking examples (D3). D3G represents extensive cracking in gable end wall, D3GF in gable end wall and front wall, D3F in front wall and D3C at the corner angle

subcategories $[1 ; 2 ; 3]$. Each subcategory represents the percentage of the collapsed element (gable end wall, front wall, roof, corner angle) as indicated in Fig. 6. If several collapses occur for a certain structural element, it is assumed to be in the "heavy damage" category (D5) (see Fig. 11). As stated, each category was further subdivided into sub-categories, according to the location of the damage observed.

For earthquake damaged buildings, commonly different types of damage coexist. In these cases, the final damage classification refers to the highest degree of damage observed. Buildings that do not present any signs of damage are catalogued as no damage (D0). To the damage related to partial collapse (D4) a new index was added (1 to 3) to characterise the percentage of the collapsed area for each damage sub-category (see Fig. 6). The available information in the database allows the combining of information regarding the structural system, constructive typology and the observed damage.

In Fig. 12 shows the results correlating the damage and construction system type. To easily analyse the results, damage is grouped in to the 5 categories as previously explained. 

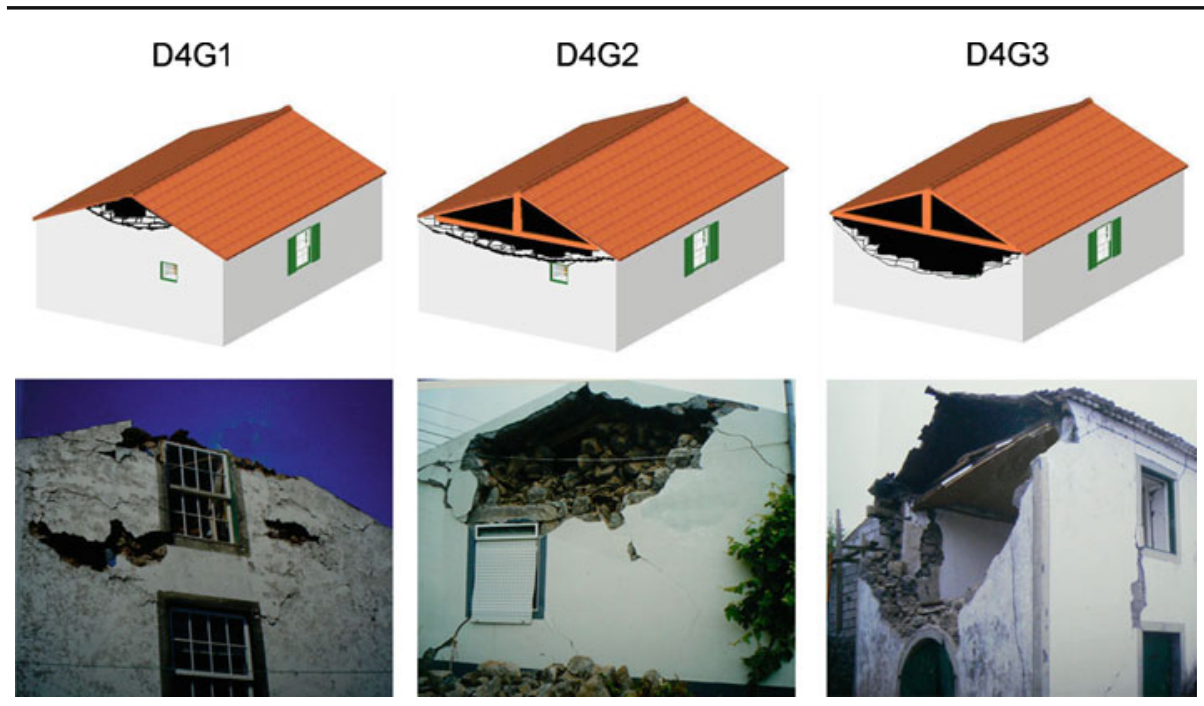

Fig. 10 Partial collapse damage in gable end wall (D4). D4G1 represents the collapse of less than $25 \%$ of total gable end wall area), D4G2 (collapse between 25 and 50\%), D4G3 (collapse between 50 and 75\%)
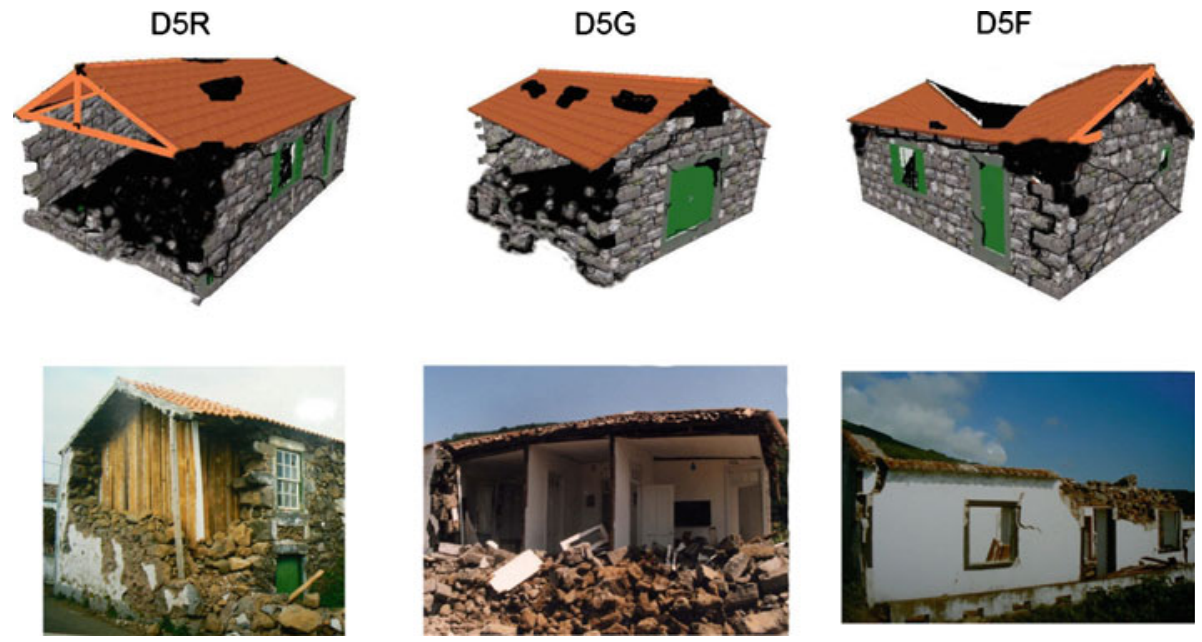

Fig. 11 Heavy damage (D5). D5R indicates the damage to the roof, D5G to the gable end wall and D5F to the front wall

\section{Vulnerability assessment methodology}

\subsection{Vulnerability index methodology}

The adopted methodology for the building vulnerability characterisation is based on the calculation of an index of vulnerability $\left(I_{v}^{*}\right)$ for each single building considering the weighted sum of 14 parameters (Vicente et al. 2010) (see Table 2). Each parameter is classified into 4 classes of increasing vulnerability: A, B, C and D. Each parameter evaluates a feature that influences the seismic performance of a seismic building. A weight $\mathrm{p}_{i}$ is assigned to each 


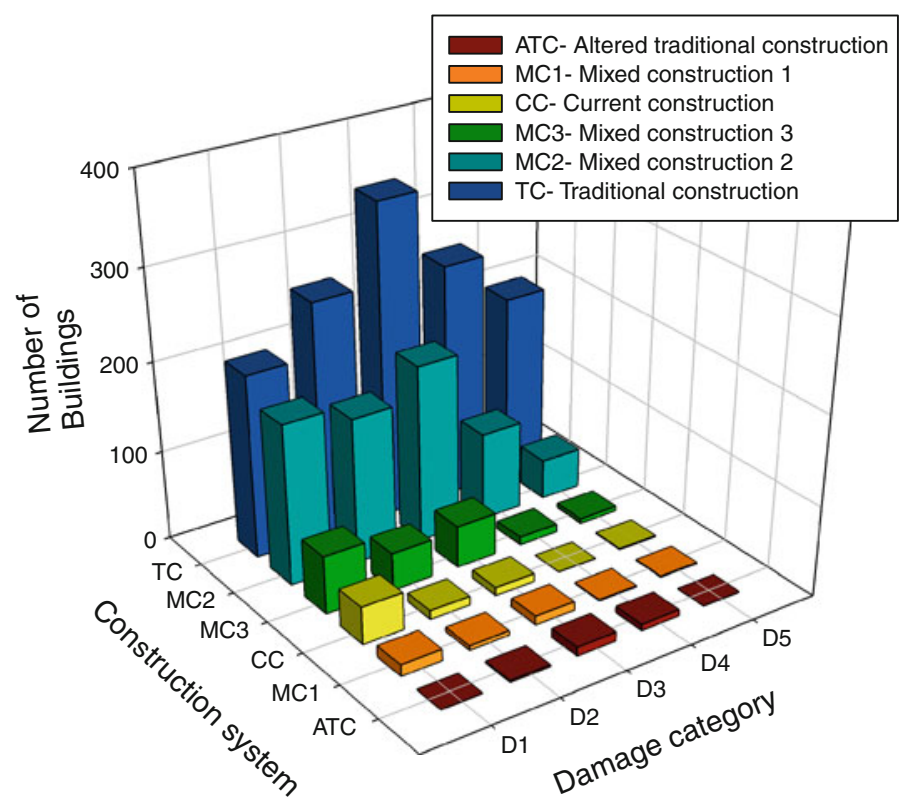

Fig. 12 Damage distribution. Relationship between damage (D1, D2, D3, D4 and D5) and the construction system type for 3,154 buildings evaluated on Faial and Pico Islands

parameter, ranging from 0.50 for the less important parameters (in terms of structural vulnerability) up to 1.5 for the most important (for example parameter P3 represents conventional strength) as shown in Table 2 . The value of the vulnerability index, $I_{v}^{*}$ can range from 0 to 812.5, however it is simpler to use a normalised vulnerability index, $I_{v}$ (ranging from 0 to 100). The calculated vulnerability index can then be used to estimate building damage for a specified macroseismic intensity level, as will be shown and discussed in Sect. 5.

The 14 parameters are grouped, as shown in Table 2, into four groups. The first group includes parameters (P1, P2) characterising the building resisting system and the type and quality of masonry, from the material (size, shape and stone type), masonry fabric and arrangement and quality of connections amongst the walls. Parameter P3 estimates the shear strength capacity of the building. Parameter P4 evaluates the potential out-of-plane collapse conditions. Parameters P5 and P6 evaluate the height and the soil foundation conditions of the buildings. The second parameter group is mainly focussed on the buildings relative location in the aggregate and on its interaction with other buildings (parameter P7). This feature is not contemplated in other methodologies and is highly important, because the building aggregate seismic response is very different from a single building response. Parameters P8 and P9 evaluate the irregularity in plan and height. Parameter P10 identifies the regularity of openings due to its importance in the load path. The third parameter group, with resource to parameters P11 and P12, evaluates horizontal structural systems, namely the type of connection of the timber floors and the impulsive nature of the pitched roofing systems. Finally, parameter P13 evaluates the structural fragilities and conservation level of the building, and parameter P14 the negative influence of non-structural elements with poor connection conditions to the main structural system.

To assess the seismic vulnerability of the building stock, all the parameters of the methodology were evaluated, however in this case, the vertical acceleration is substantial due to 
Table 2 Parameters and weights to evaluate the vulnerability index of the Azores Islands' building stock

\begin{tabular}{|c|c|c|c|c|c|c|c|}
\hline \multicolumn{2}{|c|}{ Parameters } & \multicolumn{4}{|c|}{ Class $C_{v i}$} & \multirow{2}{*}{$\begin{array}{l}\text { Weight } \\
p_{i}\end{array}$} & \multirow[t]{2}{*}{ Vulnerability index } \\
\hline & & $\mathrm{A}$ & $\mathrm{B}$ & $\mathrm{C}$ & $\mathrm{D}$ & & \\
\hline \multicolumn{6}{|c|}{ 1. Structural building system } & & $I_{\mathrm{V}}^{*}=\sum_{i=1}^{14} C_{v i} \times p_{i}$ \\
\hline $\mathrm{P} 1$ & Type of resisting system & 0 & 5 & 20 & 50 & 1.50 & \\
\hline $\mathrm{P} 2$ & Quality of the resisting system & 0 & 5 & 20 & 50 & 2.00 & \\
\hline P3 & Conventional strength & 0 & 5 & 20 & 50 & 3.00 & \\
\hline P4 & Maximum distance between walls & 0 & 5 & 20 & 50 & 0.50 & \\
\hline P5 & Number of floors & 0 & 5 & 20 & 50 & 1.50 & \\
\hline P6 & Location and soil conditions & 0 & 5 & 20 & 50 & 0.75 & \\
\hline \multicolumn{8}{|c|}{ 2. Irregularities and interaction } \\
\hline $\mathrm{P} 7$ & Aggregate position and interaction & 0 & 5 & 20 & 50 & 1.50 & \\
\hline P8 & Plan configuration & 0 & 5 & 20 & 50 & 0.75 & \\
\hline P9 & Regularity in height & 0 & 5 & 20 & 50 & 0.75 & \\
\hline P10 & Wall facade openings and alignment & 0 & 5 & 20 & 50 & 0.50 & \\
\hline \multicolumn{2}{|c|}{ 3. Floor slabs and roofs } & & & & & & $0<I v^{*} \leq 812.5$ \\
\hline P11 & Horizontal diaphragms & 0 & 5 & 20 & 50 & 1.00 & \\
\hline P12 & Roofing system & 0 & 5 & 20 & 50 & 1.00 & \\
\hline \multicolumn{2}{|c|}{ 4. Conservation status and other elements } & & & & & & Normalized index $0 \leq I_{v} \leq 100$ \\
\hline P13 & Fragilities and conservation state & 0 & 5 & 20 & 50 & 1.00 & \\
\hline P14 & Non-structural elements & 0 & 5 & 20 & 50 & 0.50 & \\
\hline
\end{tabular}

the proximity of the epicentre of the 1998 earthquake, inducing significant vertical movement contributing to a greater probability of suffering damage. Therefore, the parameters most affected by the vertical component of a seismic action were identified: (P1)-Type of resisting system, (P2) - Quality of the resisting system, (P3) - Conventional strength.

The previous parameters improved due to this particularity belong to the group that assesses the structural building system. Considering the relative weights of different parameters, parametric tests were carried out thus obtaining the following weights for parameters P1, P2 and P3, as shown in Table 2.

The weights were doubled for parameters P1, P2 and P3, compared to the weights proposed by Vicente et al. (2010). These weights were obtained due to the approximation of the distribution of vulnerability index to a normal Gaussian curve (see Vicente 2008).

Data regarding the geometric and material properties (architectural and structural design drawings of these buildings) of a set of 260 buildings was accessed (Costa 2002; Costa et al. 2008).

The vulnerability index, $I_{v}$, will allow the estimation of damage associated with a level of seismic intensity (I) (macroseismic scale, EMS 98 Grünthal 1998).

The correlation between the GNDT II method (Benedetti and Petrini 1984) and the Macroseismic method (Lagomarsino and Giovinazzi 2006) that was carried out, led to the validation of the proposed vulnerability index (Vicente 2008). The vulnerability functions from the Macroseismic method are obtained from the Eq. 1, improved by Bernardini et al. (2007) from the index of vulnerability $(V)$ of a particular building, allowing estimation of 
the mean damage grade $\left(\mu_{D}\right)$ for different macroseismic intensities given in the EMS 98 scale (Grünthal 1998).

Thus the estimated damage grade $\left(\mu_{D}\right)$ depends on the the seismic hazard described in terms of macroseismic intensity $(I)$, the vulnerability index $(V)$, a ductility factor $(Q)$ and $f(V, I)$ as defined in Eq. 2, which is a function dependent on the vulnerability index and macroseismic intensity, introduced to understand the trend of the numerical vulnerability curves derived from the EMS-98 DPM's (Damage Probability Matrix) for lower values of the intensity grades $(I=\mathrm{V}$ and $\mathrm{VI})$.

$$
\mu_{D}=2.5 \times\left[1+3 \tanh \left(\frac{I+6.25 \times V-12.7}{Q}\right)\right] \times f(V, I) ; \quad 0 \leq \mu_{D} \leq 5
$$

with

$$
f(V, I)= \begin{cases}\mathrm{e}^{\frac{v}{2}(I-7)} & I \leq V I I \\ 1 & I>V I I\end{cases}
$$

The value $(V)$ determines the position of the vulnerability curve and the ductility factor $(Q)$ determines the slope of the curve.

Since the vulnerability index of the Macroseismic method and GNDT II method are not evaluated in the same way, it is necessary to compare the two methods in order to calculate the relationship between the two vulnerability indexes $\left(I_{v}\right)$ and $(V)$ (see Vicente et al. 2010). Therefore, comparing the two vulnerability curves in relation to the average central value $\left(\mu_{D}=2.5\right)$ the relationship given in Eq. (3) was established.

$$
V=0.592+0.0057 \times I_{V}
$$

The evaluation of the vulnerability was undertaken in two phases. In a first phase, the evaluation of the vulnerability index, $I_{v}$, was carried out for the buildings for which detailed information was available (260 buildings out of 320). In a second phase, an expeditious approach has been adopted for the assessment of the remaining buildings, due to the lack of detailed geometric information. The mean value of the vulnerability index obtained for all masonry buildings from the first detailed evaluation was used as a typological vulnerability index (average value) that can be affected by modifiers of the mean vulnerability index for each building. The classification of the modifier factor can reduce or aggravate the final vulnerability index as the sum of the scores for all the modifiers. The modifiers are some of the parameters of the vulnerability index definition, as shown in Table 2. The vulnerability index is calculated based on modifier factors presented in Eq. (4).

$$
I_{v}=\bar{I}_{v}+\sum \Delta I_{v}
$$

where $I_{v}$ is the final vulnerability index; $\bar{I}_{v}$ represents the mean vulnerability index obtained from the detailed analysis and $\Delta I_{v}$ is the sum of the values of the modifier parameters (see Vicente 2008).

\subsection{Improved parameters for Azores buildings' assessment}

This improved proposal was developed to rectify the vulnerability evaluation of buildings specifically located in seismic zone type 2 according to Eurocode 8 (CEN 2008) (specific case for the Azores archipelago). Essentially two changes were made. The first change is associated with the reformulation of the parameter P3 and the second to the change of the weights (pi) for the parameters P1, P2 and P3. The parameter P3 that evaluates the conventional strength of buildings $\left(C_{\text {conv }}\right)$ using Eq. (5) was originally obtained from the GNDT II 
method (GNDT 1998) and represents a simplified ultimate verification for the safety assessment in terms of shear strength. This equation is the quantification of the overall shear strength capacity for the sum of all the masonry walls in a certain direction. To take into account the influence of the vertical seismic action in the conventional strength $\left(C_{\text {conv }}\right)$, a coefficient $\left(K_{v}\right)$ was introduced, defined in Eq. (6), to take into account the reduction of the dead load $(q)$.

$$
\begin{aligned}
C_{\text {conv }} & =\frac{a_{0} \times \tau_{k}}{q \times N} \sqrt{1+\frac{q \times N \times\left(1-K_{v}\right)}{1,5 \times a_{0} \times \tau_{k} \times(1+\gamma)}} \\
K_{v} & =\frac{S \times a_{g r} \times \frac{a v_{g}}{a_{g}}}{g}, \quad K_{v} \in[0,1],
\end{aligned}
$$

where $S$ denotes the soil foundation, depending on the EC8 seismic zone, $a_{g r}$ represents the peak ground acceleration, also defined in EC8 (CEN 2008) (for Faial Island, 2.1 seismic zone $\left.a_{g r}=2.5 \mathrm{~m} / \mathrm{s}^{2}\right)$ and $\left(a_{v g} / a_{g}\right)$ is the value that determines the vertical elastic response spectra according to EC8, for seismic action type $2, a_{v g} / a_{g}=0.95$.

\section{Vulnerability results}

The maximum value of the vulnerability index obtained by detailed analysis was 65.08 . However, the average value of $I_{v}$ is 40.71 for buildings located in rural areas and 42.76 for urban buildings. The average overall value of the vulnerability index $\left(I_{v}\right)$ is 41.62 , that indicates high vulnerability of the building stock. Buildings with a vulnerability index higher than 45 should be reassessed using more specific methods, since the consequent mean damage grade level $\left(\mu_{D}\right)$ estimated is higher than 2.5 and 3.0 for I=VII and I=VIII respectively. After applying the methodology proposed for the assessment of seismic vulnerability index, the mean damage grade $\left(\mu_{D}\right)$ was calculated for different macroseismic intensities (Grünthal 1998) using Eq. (1). In Fig. 13 the vulnerability curves for the mean value of the vulnerability index are shown, $I v$, mean, as well as for upper and lower bound ranges $I v$,mean $-2 \sigma I v$; $I v$, mean $-1 \sigma I v ; I v$,mean $+1 \sigma I v ; I v$, mean $+2 \sigma I v)$. Being $\sigma I v=9.18$, the value of standard deviation of the distribution of vulnerability index for the 260 buildings assessed in a detailed manner.

Figure 13 presents two damage scenarios that correspond to the earthquake that occurred in 1998 in the Faial Island. GIS mapping enables the identification of urban areas with higher exposure and prone to greater damage.

As for the vulnerability curves, the fragility curves (see Fig. 14b) define the relationship between the macroseismic intensity and mean damage grade, expressing the conditional probability of exceeding a certain damage grade, $D_{k}(k €[1 ; 5])$ as defined by EMS-98 (Grünthal 1998), obtained directly from the physical building damage distributions obtained using the beta probability function for a defined building typology. The probability histograms of a certain damage grade, $\mathrm{P}\left(D_{k}=d\right)$, are given by the difference of cumulative probabilities:

$$
\mathrm{P}\left(D_{k}=d\right)=\mathrm{P}\left[D_{k} \geq d\right]-\mathrm{P}\left[D_{k+1} \geq d\right]
$$

It is possible to create damage histograms for different macroseismic intensities using the average damage grade, $\left(\mu_{D}\right)$. In this study the beta probability density function was used. In Fig. 14c,d the distributions of estimated damage by using a beta distribution with geometrical parameters $(t=8),(a=0)$ and $(b=5)$ are represented for seismic intensities of VII 

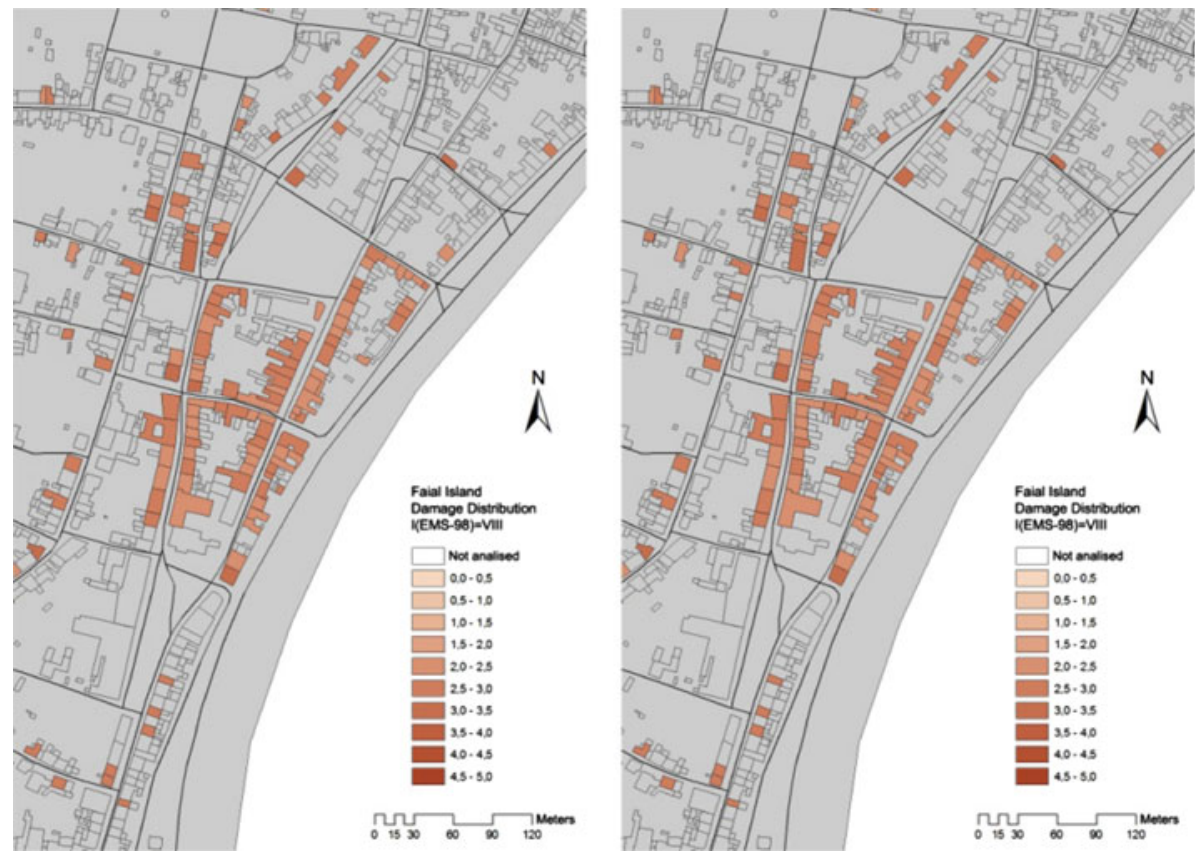

Fig. 13 Damage distribution for I(EMS-98)=VII and VIII
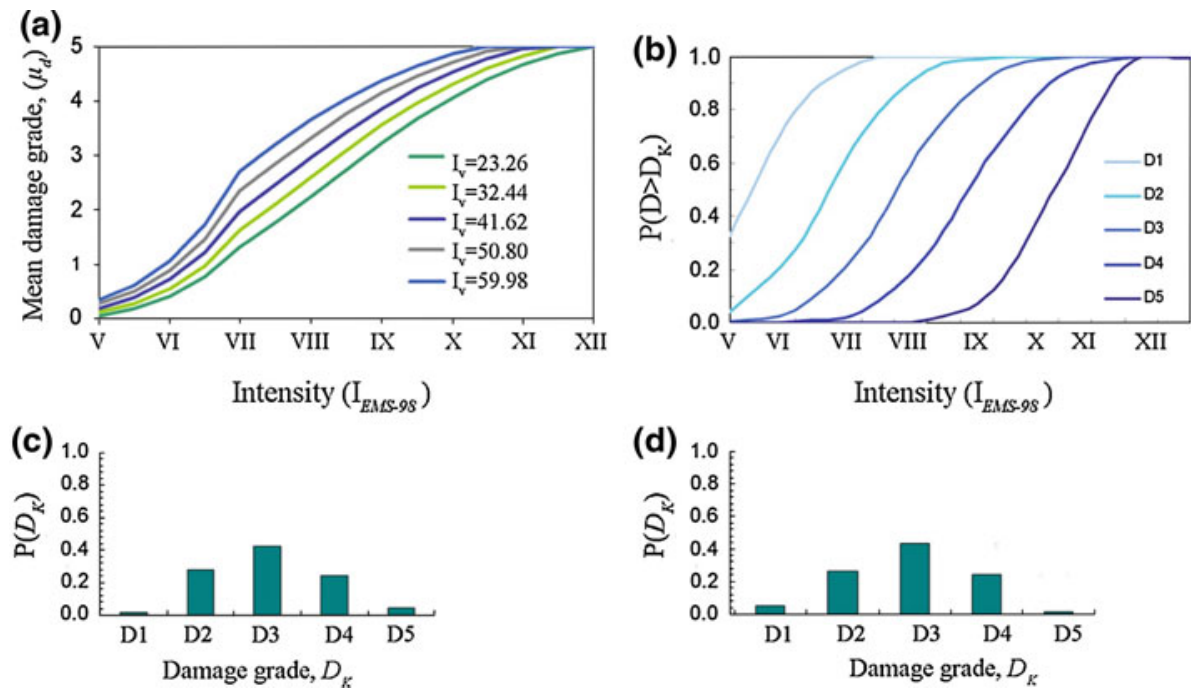

Fig. 14 Vulnerability curves, fragility curves and estimated damage distributions. a Vulnerability Curves (sample of 320 buildings); b fragility curves for $\left(I_{v}=41,62\right)$ (sample 260 buildings); $\mathbf{c}$ distribution of estimated damage for Intensity VII (EMS 98); $\mu_{D}=1,97 ; I_{v}=41,63 ; \mathbf{d}$ distribution of estimated damage for Intensity VIII (EMS 98); $\mu_{D}=2,96 ; I_{v}=41,63$ 

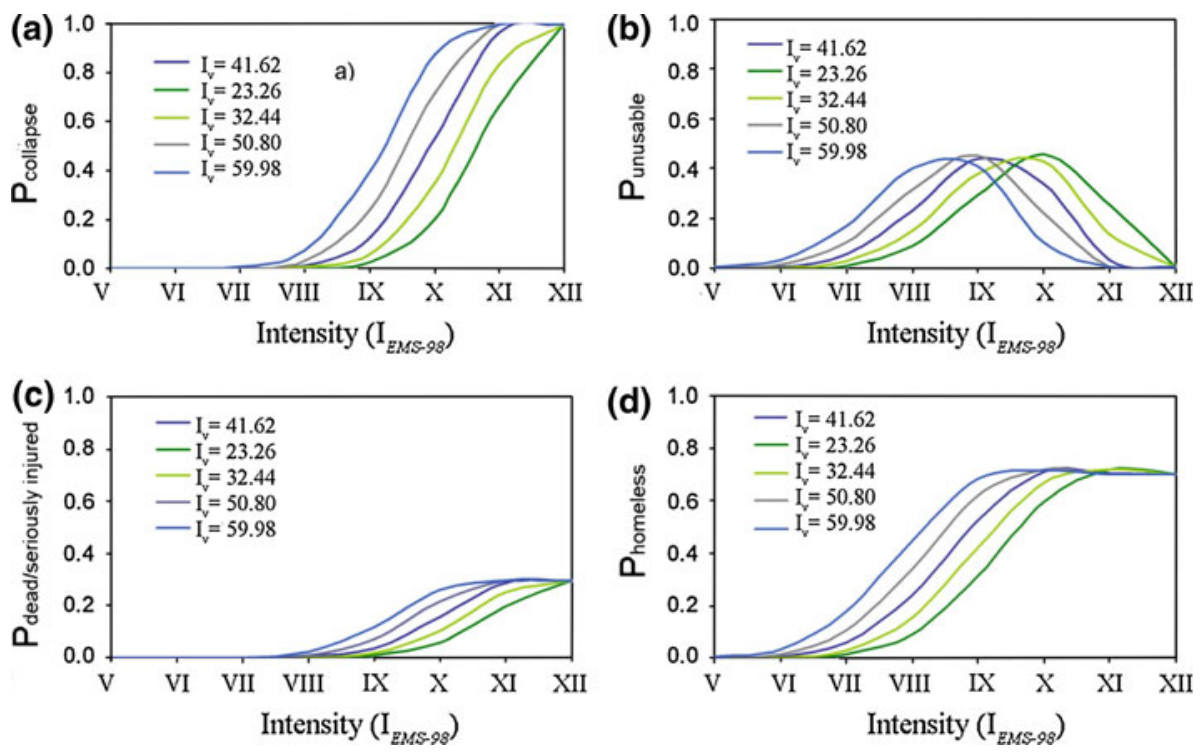

Fig. 15 Probabilistic assessment for different values of $I_{v}$, (Iv,mean $-2 \sigma I v ; I v$,mean $-1 \sigma I v ; I v$, mean $+1 \sigma I v ; I v$,mean $+2 \sigma I v$ )(sample 260 buildings). a Collapse probability for different values of $I v$; b probability of unusable buildings for different values of $I v$; $\mathbf{c}$ probability of dead/severely injured; $\mathbf{d}$ probability of homeless

(Fig. 14c) and VIII (Fig. 14d), considering the mean vulnerability $\left(I_{v}=41.62\right)$ estimated for the buildings of the Faial Island.

To assess the losses, namely the collapse and unusable building probability, the Italian National Seismic Survey proposal was adopted (Bramerini et al. 1995), based on data analysis associating the probability of unusable buildings to minor and moderate earthquakes that produce lower levels of structural and non-structural damage and higher mean damage values that are associated to the probability of collapse (Coburn et al. 1992). The loss estimation is obtained by equations that combine probabilistic damage grade values.

$$
\begin{aligned}
& \mathrm{P}_{\text {collapse }}=\left(D_{5}\right) \\
& \mathrm{P}_{\text {unusable buildings }}=\mathrm{P}\left(D_{3}\right) x W_{e i, 3}+\mathrm{P}\left(D_{4}\right) x W_{e i, 4},
\end{aligned}
$$

where $\mathrm{P}(D i)$ is the probability of a certain damage grade $(D 1)$ to $(D 5)$ and $W_{e i}$ represents the weights that define the percentage of buildings associated to the damage grade, $(\mathrm{Di})$. The following coefficients were used in Eq. (9): $W_{e i, 3}=0.4 ; W_{e i, 4}=1.0$.

The collapse probability (Fig. 15a) and unusable building probability (Fig. 15b) are represented for different values of $I_{v}$ (Iv,mean $-2 \sigma I v ; I V$,mean $-1 \sigma I v ; I v$, mean; Iv,mean $+1 \sigma I v$; $I v$, mean $+2 \sigma I v)$. It is possible to observe that the number of unusable buildings decreases with the increasing intensity, as the number of collapsed buildings increases.

To estimate the number of dead/severely injured (Fig. 15c) and homeless (Fig. 15d), the proposal of the Italian National Seismic Survey was used (Bramerini et al. 1995). These estimates were calculated using Eq. (10) and Eq. (11).

$$
\begin{aligned}
& \mathrm{P}_{\text {dead/severely injured }}=0.3 x \mathrm{P}\left(D_{5}\right) \\
& \mathrm{P}_{\text {homeless }}=\mathrm{P}\left(D_{3}\right) x W_{e i, 3}+\mathrm{P}\left(D_{4}\right) x W_{e i, 4}+0.7 x \mathrm{P}\left(D_{5}\right)
\end{aligned}
$$




\section{Conclusions}

The proposed vulnerability assessment method was adapted for its application to the Azores, revealing its universal applicability enabling the development of damage and loss scenarios for urban risk mitigation and management.

From the information gathered on the building stock, it is evident that most (57\%) of the existing buildings on the Faial Island at the time of the earthquake of 9th July 1998 were characterised by traditional construction. The exterior walls, of around $66 \mathrm{~cm}$, were made of stone masonry, the main facades are characterised by large openings for windows and doors. Floor and roof structures are mainly timber. In the interior, partition walls are usually composed of timber elements.

Regarding the observed damage after the earthquake of 1998 and after the analysis of some of the results, it is concluded that most of the damage occurred in buildings of traditional construction and the distribution of the damage is restricted to the surrounding area of the earthquake epicentre, however there were some random cases of damage to more distant buildings.

The vulnerability index method is based on a combination of a typological methodology and a conventional methodology, based on observations of damage, with a statistical basis that makes it interesting as a second level methodology (Vicente et al. 2010). Its applicability is recognised, since it is very interesting for vulnerability assessment of large areas. This methodology identifies 14 key parameters regarding the behaviour and seismic response of buildings, allowing indirect identification of structural weaknesses and common fragilities of the building stock.

The mean vulnerability index for the studied buildings is 41.62 , according to the methodology proposed. Similar studies were previously performed, in the case of Coimbra (Vicente 2008) the vulnerability index was around 38. These two cases when compared show a greater seismic risk exists in the Faial Island, when considering a hypothetical scenario of equal seismic hazard and exposure.

Through the evaluation of losses in Faial, it can be concluded that for moderate to high intensities ( $I=$ VII and $I=$ VIII) the probability of destruction of buildings is about $30 \%$ (mean of $I_{v}$ ). The probability of deaths and severe injuries occurring is low. However, about $30 \%$ of the residents are likely to become homeless.

The GIS application and database management system enables the storage of building features and survey information, assessment of seismic vulnerability and damage and risk scenario predictions, as well as allowing the upgrading and improvement of data. This integrated tool can be helpful for the development of strengthening strategies, cost-benefit analyses, civil protection and emergency planning.

In this work the effect of the vertical component of seismic action in the vulnerability of buildings was also considered. It was implemented in an equation as a contributing factor to reduce the weight of the building, consequently the decrease in the conventional strength value contributed to an increase in the global vulnerability index.

The vulnerability assessment method used is based on statistical and damage observation. However it is considered very suitable for large scale analysis since they require less information and fewer resources. Uncertainties associated with the empirical vulnerability curves and the quality of vulnerability classification data are still issues that must be studied further with respect to post-seismic data collection.

In future research, the comparison of the damage classification developed in this research and the 1998 damage survey is essential to calibrate the vulnerability functions for the old masonry building stock. 
Acknowledgments The authors thank to the anonymous reviewers for their constructive comments and suggestions that contributed to the article improvement.

\section{References}

ArcGis 9.2 (2005) Geographic Information Systems. 9esriß). 310 New York Street, Redlands, 92373 8100, USA

Benedetti D, Petrini V (1984) On seismic vulnerability of masonry buildings: proposal of an evaluation procedure. Ind Constr 18:66-78

Bernardini A, Giovinazzi S, Lagomarsino S, Parodi S (2007) Vulnerabilità e previsione di danno a scala territoriale secondo una metodologia macrosismica coerente con la scala EMS-98; ANIDIS, XII Convegno Nazionale l'ingegneria sismica in Italia, 10 a 14 Giugno, Pisa (in Italian)

Bramerini F, Di Pasquale G, Orsini A, Pugliese A, Romeo R, Sabetta F (1995) Rischio sismico del territorio italiano. Proposta per una metodologia e risultati preliminari. Rapporto tecnico del Servizio Sismico Nazionale, SSN/RT/95/01, Roma (in Italian)

Campos Costa A, Sousa ML, Carvalho A, Coelho E (2009) Evaluation of seismic risk and mitigation strategies for the existing building stock: application of LNECloss to the metropolitan area of Lisbon. Bull Earthquake Eng 8(1):119-134

CEN (2008) Eurocode 8: design of structures for earthquake resistance-Part 1: general rules, seismic actions and rules for buildings. Standardisation, European Committee for Brussels

Coburn AW, Spence R, Pomodis A (1992) Factors determining human casualty levels in earthquakes: mortality prediction in building collapse, 10th WCEE, Madrid, pp 5989-5994

Costa A (2002) Determination of mechanical properties of traditional masonry walls in dwellings of Faial Island, Azores. Earthq Eng Struct Dyn 31(7):1361-1382

Costa A, Oliveira CS, Neves F (2008) Caracterização do parque habitacional das ilhas do Faial e pico. Elementos de Estudo do Comportamento Relativo à Crise Sísmica de 9 de Julho de 1998 nos Açores. Sismo 1998 - Açores. Uma década depois, Governo dos Açores, SPRHI, S.A. (in Portuguese)

Giovinazzi S (2005) The vulnerability assessment and damage scenario in seismic risk analysis. PhD Thesis, International doctorate, University of Florence, Technical University of Carolo-Wilhelmina

Giovinazzi S, Lagomarsino S (2003) Seismic risk analysis: a method for the vulnerability assessment of built-up areas. European Safety \& Reliability Conference, Maastricht

GNDT-SSN (1994) Scheda di esposizione e vulnerabilità e di rilevamento danni di primo livello e secondo livello (muratura e cemento armato). Gruppo Nazionale per la Difesa dai Terremoti, Roma (in Italian)

GNDT-ING-SSN (1998) Critei di calcolo per la progettazione degli interventi, Verifiche sismiche ed esempi per l'applicazione delle direttive tecniche, D.G.R. Umbria 5180/98 E.D.G.R. Marche 2153/98 in attuazione L 61/98. Coordenation, Adriana de sortis; Giacomo di Pasquale; Utilio Nasini, Roma (in Italian)

Grünthal G (1998) European macroseismic scale; Centre Européen de Géodynamique et de Séismologie, Luxembourg. vol 15

Lagomarsino S, Giovinazzi S (2006) Macroseismic and mechanical models for the vulnerability assessment of current buildings. Bull Earthquake Eng 4(4):415-443

Lamas B (2003) Manual de Restauro e Recuperação/Guia do Construtor, Zona antiga da Cidade da Horta. Edição da Câmara Municipal da Horta (in Portuguese)

Lantada N, Irrizari J, Barbat AH, Goula X, Roca A, Pujades LG (2010) Seismic hazard and risk scenarios for Barcelona, Spain, using the vulnerability index method. Bull Earthquake Eng 8:201-229

Neves F (2008) Avaliação da vulnerabilidade sísmica do parque habitacional da ilha do Faial. Civil Engineering. [MSc thesis] University of Aveiro, Aveiro (in Portuguese)

Oliveira CS, Costa A, Nunes JC (2008) Sismo 1998 Açores, uma década depois, Governo dos Açores, SPRHI, S.A. ISBN 978-989-20-1223-0 (in Portuguese)

Vicente R (2008) Estratégias e metodologias para intervenções de reabilitação urbana, Avaliação da vulnerabilidade e do risco sísmico do edificado da Baixa de Coimbra. Engenharia Civil. [PhD thesis] University of Aveiro, Aveiro, Portugal (in Portuguese)

Vicente R, Parodi S, Lagomarsino S, Varum H, Mendes Silva JAR (2010) Seismic vulnerability and risk assessment: case study of the historic city centre of Coimbra, Portugal. Bull Earthquake Eng doi:10. 1007/s10518-010-9233-3

Zonno G, Oliveira C, Ferreira M, Musacchio G, Meroni F, Mota-de-Sá F, Neves F (2009) Assessing seismic damage through stochastic simulation of ground shaking: the case of the 1998 Faial earthquake (Azores Islands). Surv Geophys 31:361-381 